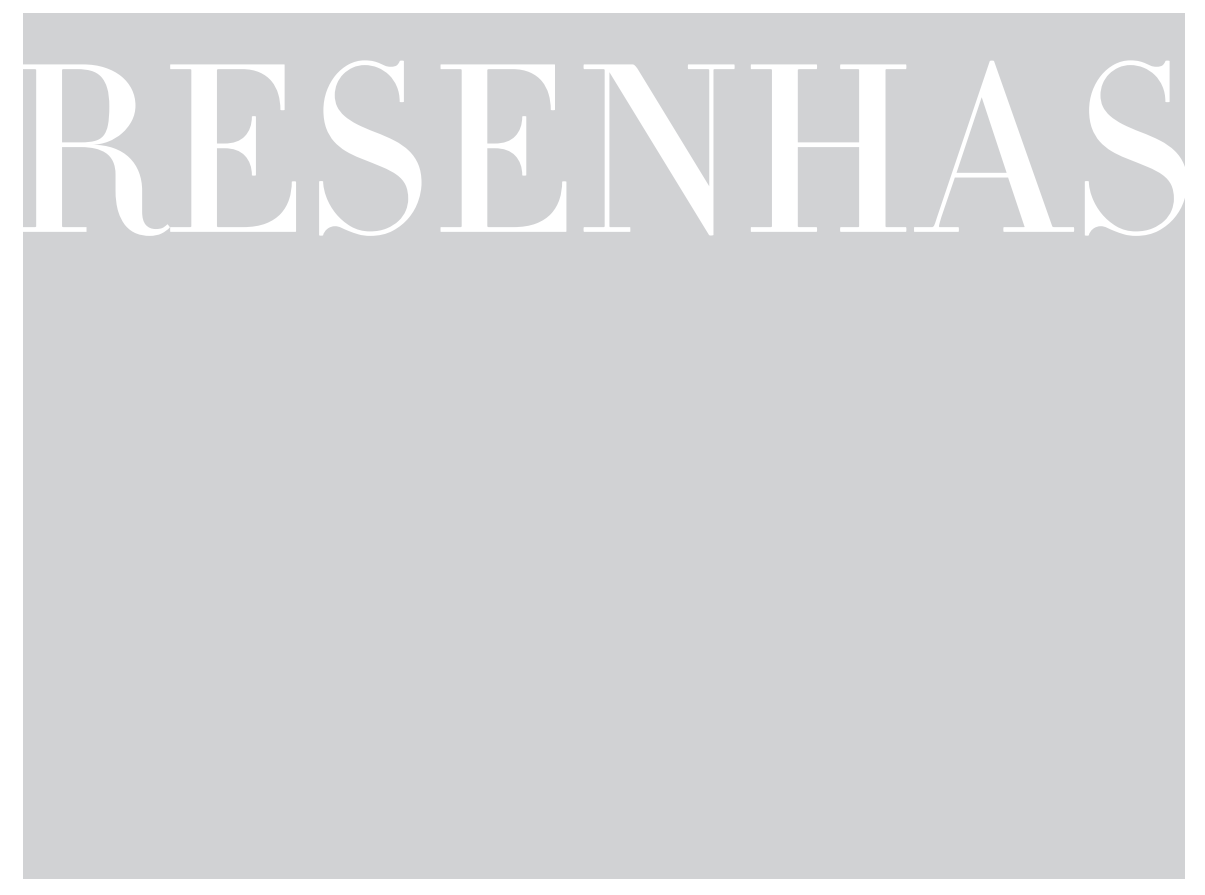

\title{
HISTORIZAR EL EJERCICIO: CORPORALIDADES Y FEMINIDAD EN ARGENTINA DESDE EL DEPORTE
}

https://doi.org/10.1590/198053145157

\section{AILIN ZOÉ BASILIO FABRIS'}

SCHARAGRODSKY, Pablo Ariel (Coord.). Mujeres en movimiento: deporte, cultura física y feminidades. Argentina, 1870-1980. Buenos Aires: Prometeo Libros, 2016. 360 p.

Reflexionar la historicidad de los cuerpos sexuados y la feminidad desde el marco de la cultura física es el objetivo de la reciente compilación elaborada por Pablo Scharagrodsky (2016), referente ineludible de los estudios sobre cultura física e historia del deporte en Argentina. El libro convoca a lectores a plantearse una serie de interrogantes circunscriptos a la notable presencia que el deporte y la cultura física han detentado sobre los procesos de configuración de los cuerpos, su sexualización, y la construcción de feminidades. Inscrito dentro de los confines de los estudios de género, en perspectiva histórica, realza la volubilidad y maleabilidad de las fronteras disciplinarias y metodológicas que atraviesan a la profesión académica.

Los trabajos reunidos en la compilación se abocan a lo fructífero de estas sinergias planteadas desde el escenario local, y bajo temporalidades distintas, deteniéndose en análisis sincrónicos y diacrónicos sobre la pluralidad de discursos, prácticas y sentidos que giraron en torno a los cuerpos en movimiento, y, a su vez, en el establecimiento de órdenes corporales generalizados en busca de ordenamiento y aleccionamiento. 
Los resultados de las investigaciones presentadas evidencian las tensiones que emergieron en el campo de la cultura física, junto con su recepción vernácula por parte de una amplia gama de actores. Su coordinador nos advierte que en Argentina el deporte se posicionó como arena de disputas, de resistencias y de oposiciones al asentamiento de pautas corporales estandarizas, ambicionando una demarcación en el reconocimiento, la distinción y el retraimiento de corporalidades consideradas "normales" frente a otras “abyectas”. El deporte, por lo tanto, desempeñó funciones de árbitro y juez de los cuerpos, diseñando, de esta manera, regímenes de sexualidad, corporalidad y comportamiento de los sujetos que participaban, o no, de él.

Parte de la propuesta de la compilación es explorar la llegada de saberes, prácticas, discursos, sentidos y conocimientos sobre el deporte y el movimiento físico a la Argentina. La multiplicidad de apropiaciones de estas aristas fueron resignificadas en una vorágine de procesos: desde la prescripción y la penalización, hasta la represión y la interdicción de cuerpos y experiencias conmutadas por una variedad de intérpretes que cohabitaron los diversos espacios sociales, en los que sobresalen los religiosos, los periodísticos, los biomédicos y los militares. El libro, entonces, bucea en esta heterogeneidad de asimilaciones de la cultura física, que aluden a contemplar el decurso y el despliegue de transacciones y mecanismos que asentaron una disparidad de contrastes sobre la(s) feminidad(es) a lo largo de cien años de historia argentina.

Bajo estos considerandos, la compilación propone una división de acuerdo a los discursos y los saberes que dominaron la regulación, la administración y el adiestramiento de los cuerpos desde el marco de la cultura deportiva. Su objetivo es promover un raciocinio crítico y reflexivo en torno a la construcción social e histórica de la sexualidad, la corporalidad y lo femenino. La cultura física y la(s) mujer(es) son los motores que vehiculizan, a través de temáticas diferentes, pero enlazadas, una propuesta a fin de rastrear las contradicciones, las uniones, las asperezas y las fricciones que atravesaron a distintos actores, privados y públicos, en duraciones diacrónicas y sincrónicas.

Cada sección está compuesta por una rica variedad de trabajos que exploran distintas aristas del eje en cuestión. La primera parte, nominada Cultura física, discurso biopolítico y construcción de feminidades, nuclea producciones centradas en desandar las tramas que agrupan al deporte, al género y a los saberes médicos. Se plantea en ella cómo el deporte, las mujeres y la feminidad fueron seminales para el campo de la medicina. Desde este ámbito, la cuestión de la salud, el bienestar, y la función reproductiva de las mujeres, fueron tópicos atractivos en las postrimerías decimonónicas e inicios del nuevo siglo. La rúbrica del deporte forjó rejillas heteronormativas y heterosexuales para definir 
y establecer pautas de sociabilidad, circulación, comportamiento y actuación en la construcción del Estado argentino.

El trabajo de Diego Armus propone una aproximación a las heterogéneas posiciones médicas en torno al consumo, uso y aplicación del corsé en las postrimerías decimonónicas y primeras décadas del siglo XX, enfocándose en su tratamiento a nivel mediático. Las fisuras y disputas por el uso de la prenda partían de posiciones eugenésicas y estéticas, pero que convergían y ratificaban su usufructo para el aseguramiento de matrimonios longevos y de la salud reproductiva de las mujeres. La posesión y la efectividad del corsé recaían en las mujeres, quiénes eran alentadas a utilizarlo en la búsqueda de pareja y la concreción del matrimonio.

El libro cuenta con un trabajo de carácter homónico y colaborativo centrado en la recepción local de la gimnasia portada por Ruth Schwartz de Morgenroth a la Argentina durante las décadas de los treinta, cuarenta y cincuenta. Su figura es recuperada por Pablo Scharagrodsky y Andrés H. Reggiani para explorar la llegada y la consolidación de una gimnasia radicada a medio camino de saberes médicos y psicológicos e influencias espiritualistas orientales, instalando un binomio consustancial entre el deporte y la maternidad y una educación corporal dirigida a mujeres.

Eugenia Tarzibachi bucea en la habilitación gradual de la menstruación dentro del campo de la cultura física. Su trabajo indaga en el exiguo estudio del período menstrual, su relación con el deporte, la inclusión de productos de "cuidado personal femenino" y su aplicación para las instancias de movimiento. Su artículo recorre la integración y aplicación de toallas femeninas; la pedagogía médica sobre el cuerpo menstruante, la recreación y el deporte, y las tensiones que afloran en la convalidación progresiva de menstruar y estar en movimiento.

La penúltima producción se centra en el análisis de los discursos médicos anarquistas y sus disputas y lecturas sobre el ejercicio sexual en términos de salud y enfermedad. Nadia Ledesma Prietto profundiza en las narraciones galenas en torno a la sexualidad y lo físico, transitando en la pauta de la doble moral sexual que imperaba histórica y discursivamente en los espacios médicos, trasladándola al campo de la cultura física, y su cuestionamiento desde médicos anarquistas en las décadas del treinta y cuarenta.

El trabajo que da cierre a este apartado propone adentrarnos a las etimologías sociales, culturales y de género que habitan dentro del campo de la cultura física. Andrés Reggiani sintetiza los recorridos que el deporte transitó históricamente desde su constitución como actividad, poniendo el acento en su articulación con la dirección y la administración del cuerpo femenino. El autor destaca el papel dominante de la biotipología y la medicina constitucional dentro del espacio de 
la cultura física, ocupándose de su imbricación con lo femenino y lo reproductivo.

La segunda parte, Cultura física, discurso religioso y construcción de feminidades, se centra en las articulaciones acontecidas entre los sectores religiosos y la cultura física, lo que incluyó la resignificación e instalación de movimientos de circulación internacional, como el scoutismo, y la concepción de sus delegaciones como territorios para diseminar sentidos y prescripciones sobre lo corporal.

Miranda Lida da inicio a este apartado temático con una investigación acerca del ensamblaje entre catolicismo, ocio y deporte en la Ciudad de Buenos Aires durante el período de entreguerras. La autora hace mención al importante papel que la Iglesia Católica le otorgó al deporte, asimilándolo en base a los géneros y a los “riesgos” morales y nacionalistas que podía portar.

Continuando la línea de investigación iniciada por Lida, Patricia Anderson propone estudiar la Asociación Cristiana Argentina de Buenos Aires como propulsora de la equidad de género, la educación corporal y la cultura física. La autora destaca las asociaciones y actividades deportivas impulsadas por las integrantes de la Asociación Cristiana Femenina, quienes buscaban realizar un llamamiento de reconocimiento simbólico y material para aquellos espacios que les eran social y jurídicamente denegados. En torno al deporte, estas mujeres dieron especial importancia a la administración, la regulación y el disciplinamiento de sus cuerpos.

La fundación del scoutismo en Argentina se concreta a comienzos en la segunda década del Siglo XX. Su recepción local fue resignificada a través de la apropiación y reconversión de narraciones nacionalistas en cuerpos patrióticos y disciplinados. Laura Méndez indaga en el desembarco del scoutismo en nuestro país, su expansión a instituciones educativas, y la consolidación de la participación femenina en él en base a un supuesto de género: las mujeres podían ingresar a la Asociación Scout y llevar adelante los principios del scoutismo, pero su participación era registrada en términos reproductivos y de estereotipos y roles a cumplir.

Por último, el trabajo de Adrián Cammarota y Karina Ramacciotti reflexiona sobre la relación entre catolicismo, scoutismo y asociacionismo juvenil a la hora de forjar valores de disciplinamiento y regulación del cuerpo en el tiempo libre, propugnando la construcción de una masculinidad y una feminidad en los campamentos católicos. Ambos autores navegan por los claro oscuros de la Iglesia Católica en Argentina, ocupándose de su rol en la gestión del cuerpo y la sexualidad en los jóvenes campistas católicos.

El tercer y último apartado, Cultura física, deporte, prensa $y$ construcción de feminidades, agrupa una serie de trabajos que ponen el 
acento en la participación de las mujeres en deportes que han sido históricamente ocupados por hombres, y aquellos de carácter reciente. Por otro lado, la preocupación por la confección del cuerpo femenino a través de la cultura física en la prensa, propone una indagación sobre lo que los términos mujer y modernidad condensan en el siglo XX.

Las primeras dos producciones abordan la inclusión y el desenvolvimiento de las mujeres en espacios donde la cultura física se proyectaba desde lo masculino. Roy Hora traza el desenvolvimiento y la conformación histórica de las relaciones entre hombres y equinos, hasta arribar en la constitución del turf. El asentamiento de hipódromos ofició, por un lado, como enclave de sociabilización, distinción y pasarela de la elite porteña, y, por el otro, como ámbito de esparcimiento de los sectores de menos ingresos. El aporte más interesante de este trabajo es la mixtura entre clase y género, y el espesor que este deporte tuvo en Argentina: las mujeres locales sólo emergían para los eventos que rodeaban al Jockey Club, y que, a diferencia de los hombres, no participaban del circuito de apuestas ni de las carreras, relegándolas a un plano meramente estético y de postal del deporte.

Por otro lado, Dora Barrancos relata la vida de las primeras aviadoras a comienzos del Siglo XX, arrojando luz sobre la actuación temprana de las mujeres en la aviación. La autora alumbra un territorio en donde la incursión de las mujeres al mando de un artefacto aéreo fue temprano, internacional, continental y local. Una serie de aviadoras, desde Francia hasta Bolivia y Argentina, tomaron posesión de la actividad aeronáutica y lograron reconvertirla en un deporte que trascendiese el esparcimiento, colocándola como una profesión viable para las mujeres pero, a su vez, se vieron encorsetadas en el desarrollo de la actividad por los prejuicios genéricos.

El nacimiento de la práctica de tiro en Argentina en la transición al nuevo siglo XX, se vio envuelto de fenómenos y climas heterogéneos. Diego Roldán analiza la génesis de esta actividad deportiva en dos marcos históricos divergentes, pero que confluyeron en la exhibición y el fortalecimiento de sentidos heteronormativos: por un lado, el tiro no fue una invención del discurso nacionalista a fines de siglo, sino una práctica importada por las nuevas colonias y comunidades inmigrantes del interior del país. Por otro lado, la consolidación del Ejército Argentino, en donde el adiestramiento del cuerpo, masculino en particular, se solapó con la legislación y políticas públicas abocadas a moldear ciudadanos con identidades y afinidades de orden nacional y patriótico. En un resquicio de esta cultura castrense, las mujeres transitaron desde espacios plenamente pasivos hasta su inmersión en las armas en torneos femeninos subordinados a normativas masculinas.

Por último el trabajo de Paula Bontempo, quién se aleja del diseño del deporte en Argentina para acercarse al rol protagónico de las 
mujeres en la prensa gráfica durante las primeras tres décadas del siglo $\mathrm{XX}, \mathrm{y}$ ahondar en la resignificación de las mujeres y el deporte, junto con un establecimiento de una modernidad para el cuerpo femenino.

Las casi 400 páginas que componen Mujeres en movimiento, resultan un insumo indispensable para quienes nos dedicamos a investigar las disposiciones de género que rigen en los diversos ámbitos disciplinarios y de acción social de los sujetos. Por otro lado, el lanzamiento de esta compilación pavimenta el camino hacia una agenda preocupada por entender la constitución de los cuerpos y la sexualidad desde una perspectiva histórica.

La labor cristalizada por Pablo Scharagrodsky en esta compilación cumple su objetivo inicialmente planteado: poner en movimiento, mental y corporalmente, la reflexión crítica sobre la maleabilidad de los cuerpos, su transformación, reconversión y constitución histórica. Los trabajos aquí reunidos oxigenan el campo de los estudios de género gracias a su capacidad de congregar variedades disciplinarias y metodológicas, sin perder nunca la unidad y el hilo del relato, y así proponer abordajes posibles para los presentes y futuros investigadores. Las producciones puestas a dialogar dan cátedra de las urdimbres que enlazan a la cultura física, al género y a los discursos como campo fecundo de las Ciencias Sociales.

\section{REFERÊNCIAS}

SCHARAGRODSKY, Pablo Ariel (Coord.). Mujeres en movimiento: deporte, cultura física y feminidades. Argentina, 1870-1980. Buenos Aires: Prometeo Libros, 2016. 